\title{
Fabrication of Vertical-Standing Co-MOF Nanoarrays with 2D Parallelogram-like Morphology for Aqueous Asymmetric Electrochemical Capacitors
}

\author{
Leyuan Li, Hongtian Mi, Yuhong Jin *, Dayong Ren, Kailing Zhou, Qianqian Zhang, Jingbing Liu and Hao Wang *
}

check for

updates

Citation: Li, L.; Mi, H.; Jin, Y.; Ren, D.; Zhou, K.; Zhang, Q.; Liu, J.; Wang, H. Fabrication of Vertical-Standing Co-MOF Nanoarrays with 2D Parallelogram-like Morphology for Aqueous Asymmetric Electrochemical Capacitors. Molecules 2021, 26, 5394. https://doi.org/ $10.3390 /$ molecules26175394

Academic Editor: Carlo Santoro

Received: 4 August 2021

Accepted: 2 September 2021

Published: 5 September 2021

Publisher's Note: MDPI stays neutral with regard to jurisdictional claims in published maps and institutional affiliations.

Copyright: (c) 2021 by the authors. Licensee MDPI, Basel, Switzerland. This article is an open access article distributed under the terms and conditions of the Creative Commons Attribution (CC BY) license (https:// creativecommons.org/licenses/by/ $4.0 /)$.
Key Laboratory for New Functional Materials of Ministry of Education, Institution of Advanced Energy Materials and Devices, Faculty of Materials and Manufacturing, Beijing University of Technology, Beijing 100124, China; Lileyuan@emails.bjut.edu.cn (L.L.); ustbmht@163.com (H.M.); rendayong1@emails.bjut.edu.cn (D.R.); zkling@emails.bjut.edu.cn (K.Z.); zhangqianqian@bjut.edu.cn (Q.Z.); liujingbing@bjut.edu.cn (J.L.) * Correspondence: jinyh@bjut.edu.cn (Y.J.); haowang@bjut.edu.cn (H.W.); Tel.: +86-010-67396288 (Y.J. \& H.W.)

\begin{abstract}
Metal organic frameworks (MOFs) have been considered as one of the most promising electrode materials for electrochemical capacitors due to their large specific surface area and abundant pore structure. Herein, we report a Co-MOF electrode with a vertical-standing 2D parallelogram-like nanoarray structure on a $\mathrm{Ni}$ foam substrate via a one-step solvothermal method. The as-prepared CoMOF on a Ni foam electrode delivered a high area-specific capacitance of $582.0 \mathrm{mC} \mathrm{cm}^{-2}$ at a current density of $2 \mathrm{~mA} \mathrm{~cm}^{-2}$ and a good performance rate of $350.0 \mathrm{mC} \mathrm{cm}^{-2}$ at $50 \mathrm{~mA} \mathrm{~cm}^{-2}$. Moreover, an asymmetric electrochemical capacitor (AEC) device (Co-MOF on Ni foam/ / AC) was assembled by using the as-prepared $\mathrm{Co}-\mathrm{MOF}$ on a $\mathrm{Ni}$ foam as the cathode and a active carbon-coated $\mathrm{Ni}$ foam as the anode to achieve a maximum energy density of $0.082 \mathrm{~mW} \mathrm{~cm}^{-2}$ at a power density of $0.8 \mathrm{~mW} \mathrm{~cm}^{-2}$, which still maintained $0.065 \mathrm{~mW} \mathrm{~cm}^{-2}$ at a high power density of $11.94 \mathrm{~mW} \mathrm{~cm}^{-2}$. Meanwhile, our assembled device exhibited an excellent cycling stability with a capacitance retention of nearly $100 \%$ after 1000 cycles. Therefore, this work provides a simple method to prepare MOF-based material for the application of energy storage and conversion.
\end{abstract}

Keywords: metal organic frameworks; Co-MOF; nanoarrays; asymmetric electrochemical capacitors

\section{Introduction}

Nowadays, in order to fight climate change and promote green, low-carbon development, developing renewable energy sources, such as wind energy, solar energy, geothermal energy, tidal energy, has been considered as one of the most promising and effective ways to decrease the greenhouse gas emission [1-3]. However, these renewable energy sources are intermittent and uncontrollable. Therefore, it is very urgent to explore a reliable electrochemical energy storage device to efficiently store these renewable energy sources. Among these electrochemical energy storage devices, electrochemical capacitors have drawn remarkable attention owing to their high power density and long cycling stability along with fast energy storage ability [4-7]. According to the mechanism of energy storage, electrochemical capacitors are classified into electric double-layer capacitors (EDLCs) with the physical adsorption of ions and pseudocapacitors with the electron transfer reaction. EDLCs that usually use carbon-based electrode materials display high power density and excellent cycling performance but deliver a low capacitance. In contrast, pseudocapacitors have the high energy density with the poor cyclic stability and unsatisfied power density [8,9]. Therefore, it is of great importance to improve the energy density of the electrochemical capacitors accompanied with the high power density and long cycling stability.

Recently, asymmetric electrochemical capacitors (AECs) have been designed as a new single-energy storage device, which integrates a high battery-like energy density electrode 
and an EDLC electrode [10-12]. Due to the utilization of the battery-like electrode and the wide working voltage range, AECs can simultaneously improve the energy/power density [13]. Thus, it should be noted that the study on the battery-like electrode materials plays a crucial role for high-performance AECs.

Compared with the traditional battery-like electrode materials, such as transition metal oxides [14,15], sulfides [16], hydroxides [17], phosphides [18-20], selenides [21,22], and even conducting polymers [23-25], metal organic frameworks (MOFs) have become a research hotspot for the application of electrochemical capacitors due to their large specific surface area, abundant pore structure, and different active transition metal ions including $\mathrm{Fe}, \mathrm{Co}, \mathrm{Cu}$, and $\mathrm{Ni}$ [26-29]. So far, it is very popular to take advantage of MOFs as a template to prepare different derivatives via the high-temperature treatment process because it can be easy to obtain carbon-coated active transition metal-based composites [30-32]. Nevertheless, the framework structure of MOFs is inevitably destroyed during the pyrolytic process, which can significantly reduce the specific surface area and redox active sites. Thus, it can be expected that the advantage of the pristine MOFs may be achieved by the direct application as an electrode material for electrochemical capacitors. However, pristine MOFs exhibit low intrinsic electrical conductivity, which limits their application in electrochemical capacitors.

In order to deal with this problem, Dinca's group [33] designed a conductive pristine MOF from the regulation of the molecular structure for super capacitive applications. A MOF $\mathrm{Ni}_{3}(2,3,6,7,10,11 \text {-hexaiminotriphenylene })_{2}\left(\mathrm{Ni}_{3}(\mathrm{HITP})_{2}\right)$ with high electrical conductivity and high porosity displayed a specific area capacitance of $18 \mu \mathrm{F} \mathrm{cm}^{-2}$ and good capacity retention of $90 \%$ for 10,000 cycles. It could be found that $\mathrm{Ni}_{3}(\mathrm{HITP})_{2}$ exhibited a EDLC mechanism with a low capacitance. Another strategy used to improve the electrical conductivity of MOFs is combined with different carbon materials. Azadfalah and coworkers [34] reported a Co-based MOF with graphene (CoMG) nanocomposite via a one-step method. The CoMG nanocomposite delivered a high specific capacitance of $549.96 \mathrm{~F} \mathrm{~g}^{-1}$ at $1.0 \mathrm{~A} \mathrm{~g}^{-1}$. The asymmetric-activated carbon-CoMG device exhibited a specific energy of $8.1 \mathrm{Wh} \mathrm{kg}^{-1}$ at $850 \mathrm{~W} \mathrm{~kg}^{-1}$ with a long cycle life of $78.85 \%$ capacitance retention after 1000 cycles at $1 \mathrm{~A} \mathrm{~g} \mathrm{~g}^{-1}$, yet the addition of inactive carbon (including in the composite and conductive carbon black) and binder for the assembly of an electrode on the current collector would decrease the capacitance value of the as-prepared composites. Recently, $\mathrm{Xu}$ and coworkers [35] designed a hierarchical layered structure of CoNi-MOF with ultrathin nanosheets and nanotube arrays on a carbon cloth (CC/CoNi-MOF). $\mathrm{ZnO}$ nanorods, as a sacrificial template, were firstly deposited on the $\mathrm{CC}$, and then $\mathrm{Co}(\mathrm{OH})_{2}$ nanosheets were coated on $\mathrm{ZnO}$ nanorods via an electrodeposition method. Finally, $\mathrm{Co}(\mathrm{OH})_{2}$ was thoroughly changed into CoNi-MOF in the nickel nitrate hexahydrate and p-benzenedicarboxylic as an organic links system via a hydrothermal process. As-prepared CC/CoNi-MOF exhibited a high areal capacity of $1.01 \mathrm{C} \mathrm{cm}^{-2}$ at a current density of $2 \mathrm{~mA} \mathrm{~cm}-2$ with a high energy density of $55.5 \mathrm{Wh} \mathrm{kg}^{-1}$ at $175.5 \mathrm{~W} \mathrm{~kg}^{-1}$ for the AEC device. The good electrochemical capacitive performance could be attributed to the intimate contact between CoNi-MOF, CC, and the 2D nanosheet-like structure, which could enhance the electron and ion transportation.

Inspired by this work, in order to design a simple method for the preparation of $2 \mathrm{D}$ MOF arrays on the conductive substrate, we developed a Co-MOF electrode with verticalstanding 2D parallelogram-like nanoarray structure on a $\mathrm{Ni}$ foam substrate via a one-step solvothermal method. As-prepared $\mathrm{Co}-\mathrm{MOF}$ on a $\mathrm{Ni}$ foam electrode delivered a large area specific capacitance of $582.0 \mathrm{mC} \mathrm{cm}^{-2}$ at a $2 \mathrm{~mA} \mathrm{~cm}^{-2}$, while maintaining a $60.1 \%$ capacity retention at $50 \mathrm{~mA} \mathrm{~cm}^{-2}$. Moreover, as for AES device, a maximum energy density was as large as $0.082 \mathrm{~mW} \mathrm{~cm}^{-2}$ at a power density of $0.8 \mathrm{~mW} \mathrm{~cm}-2$ along with an excellent cycling stability (a capacitance retention of nearly 100\% after 1000 cycles). 


\section{Results and Discussion}

Figure 1 exhibits the synthetic process for 2D parallelogram-like Co-MOF on $\mathrm{Ni}$ foam through one-step solvothermal method. Briefly, $\mathrm{CoCl}_{2} \cdot 6 \mathrm{H}_{2} \mathrm{O}$ and PTA were completely dispersed into a mixed solvent of DMF and high-purity water. During the reaction process in the autoclave at $120{ }^{\circ} \mathrm{C}$, the color of $\mathrm{Ni}$ foam went from the original silver-gray to light-brown, which means that the Co-MOF material was grown on the surface of Ni foam.

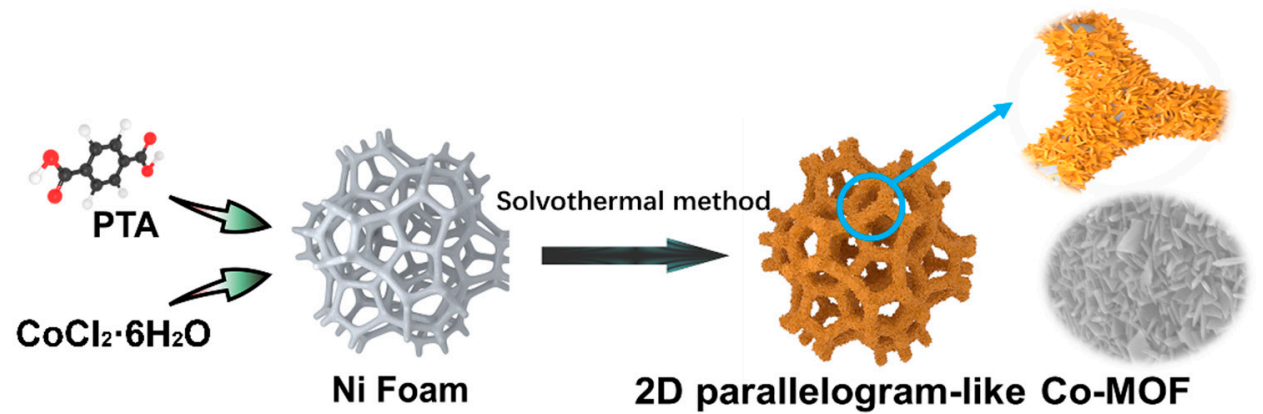

Figure 1. Schematic diagram of the synthetic process for 2D parallelogram-like Co-MOF on Ni foam.

\subsection{Structure Characterization of As-Prepared Co-MOF on Ni Foam}

Figure 2 exhibits the XRD pattern of as-prepared 2D parallelogram-like Co-MOF on Ni foam. The diffraction peaks at $44.8^{\circ}, 52.0^{\circ}$, and $76.5^{\circ}$ are attributed to the nickel (PDF\#700989) from the Ni foam substrate. Meanwhile, it can be observed that the $2 \theta$ values of the peaks at $8.8^{\circ}, 15.8^{\circ}, 17.9^{\circ}, 30.7^{\circ}, 32.8^{\circ}$, and $45.7^{\circ}$ belong to the cobalt terephthalate hydroxide $\left(\mathrm{Co}_{2}(\mathrm{OH})_{2}\left(\mathrm{C}_{8} \mathrm{H}_{4} \mathrm{O}_{4}\right)\right)$ phase, in agreement with the simulated crystal data from PDF\#34-1897 [36,37]. These results confirm that Co-MOF was successfully deposited on $\mathrm{Ni}$ foam via a simple solvothermal method. In addition, the organic functional groups of as-prepared 2D parallelogram-like Co-MOF are confirmed by the FT-IR spectrum, as shown in Figure $2 \mathrm{~b}$. The absorption band at $3596 \mathrm{~cm}^{-1}$ is assigned to the $\mathrm{O}-\mathrm{H}$ stretching vibration, while the two main bands at 1589 and $1352 \mathrm{~cm}^{-1}$ are attributed to antisymmetric and symmetric - $\mathrm{COO}$ functional groups, respectively [38-40]. Another three absorption bands at 1095,1012 , and $804 \mathrm{~cm}^{-1}$ correspond to $\mathrm{C}-\mathrm{H}$ vibration in aromatic rings $[36,41]$.
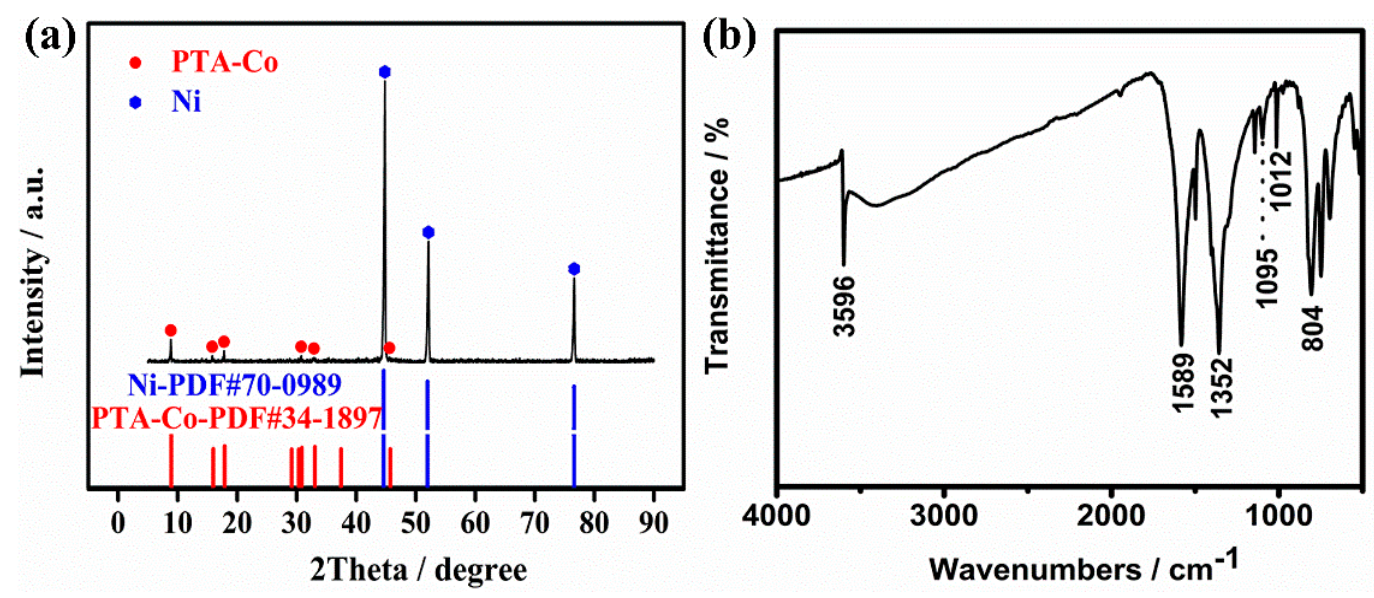

Figure 2. (a) XRD pattern and (b) FT-IR spectra of 2D parallelogram-like Co-MOF on Ni foam.

XPS measurements are also used to further confirm the surface elemental states of as-prepared 2D parallelogram-like Co-MOF on Ni foam. As shown in Figure 3a, XPS survey spectrum exhibits $\mathrm{Co}, \mathrm{Ni}, \mathrm{C}$, and $\mathrm{O}$ peaks. The existence of Ni peak is attributed to the Ni substrate. Figure $3 \mathrm{~b}$ shows the high-resolution XPS spectrum of $\mathrm{C} 1 \mathrm{~s}$. It can 
be resolved into three peaks at binding energies of 284.6, 285.7, and $288.4 \mathrm{eV}$, which can be ascribed to $\mathrm{C}=\mathrm{C}, \mathrm{C}-\mathrm{H}$ and $\mathrm{O}-\mathrm{C}=\mathrm{O}$ groups for PTA ligand at $\mathrm{Co}-\mathrm{MOF}$ materials [42]. Meanwhile, the high-resolution XPS spectrum of $\mathrm{O} 1 \mathrm{~s}$ is shown in Figure 3c. The peaks at 531.7 and $532.6 \mathrm{eV}$ are identified as the coordination between the $\mathrm{O}-\mathrm{Co}$ and $\mathrm{C}=\mathrm{O}$ groups in PTA ligands, respectively. For the high-resolution XPS spectrum of Co 2p, two main peaks at binding energies of 797.6 and $781.4 \mathrm{eV}$, accompanied with two shake up satellites at 802.9 and $785.9 \mathrm{eV}$ for Co 2p1/2 and Co 2p3/2 (names as "Sat."), respectively, can be observed [43]. It is well known that the binding energy gap between the main peak and the satellite peak is considered as an important parameter to confirm the oxidation of transition metals [44]. As for the Co (II), the energy gap is within $6 \mathrm{eV}$. Based on these analyses, we can conclude that the chemical valence of Co ions in our 2D parallelogram-like Co-MOF on $\mathrm{Ni}$ foam is predominantly $2+$.
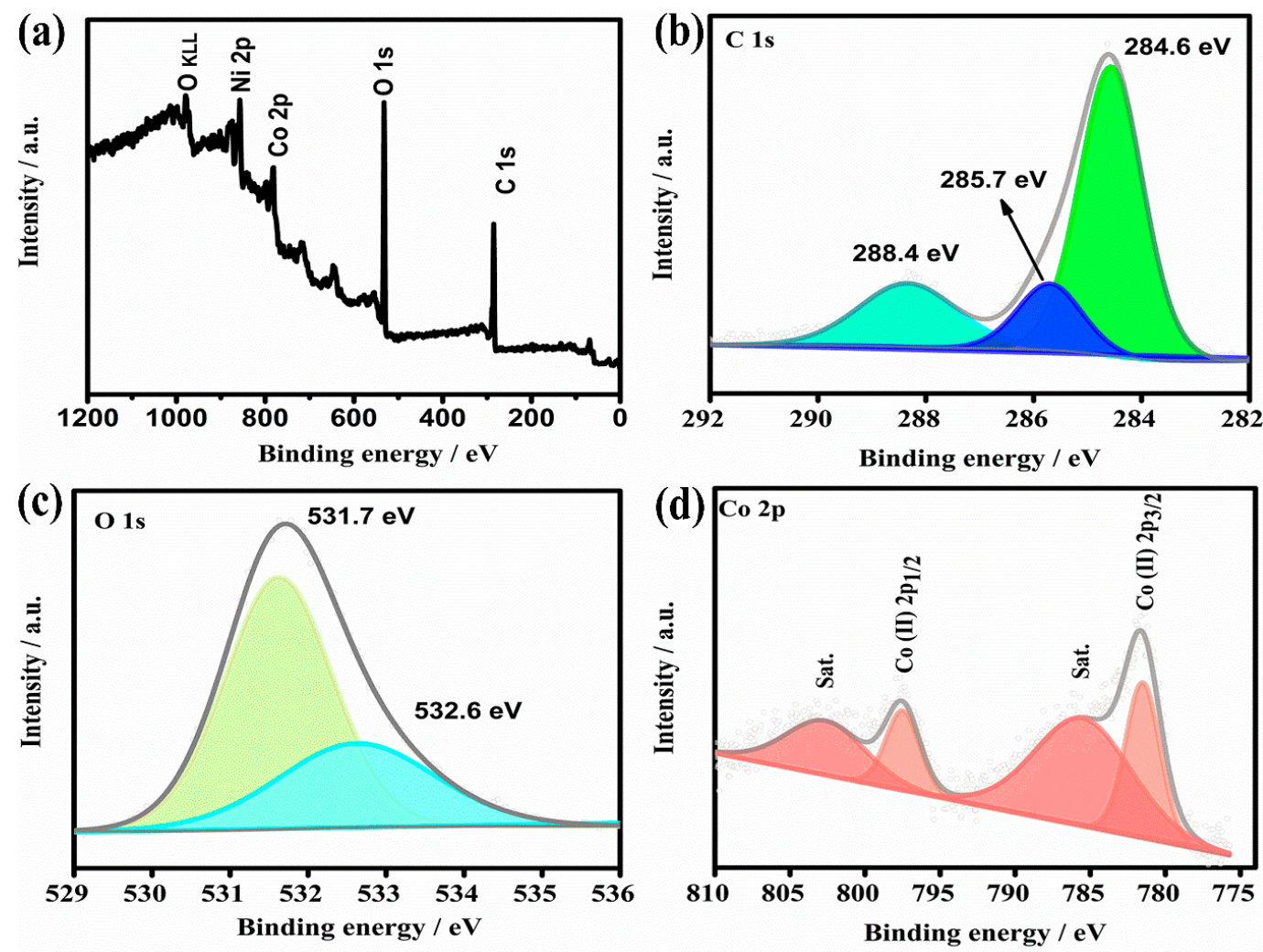

Figure 3. (a) XPS survey spectrum, (b) C 1s, (c) O 1s and (d) Co 2p region of 2D parallelogram-like Co-MOF on Ni foam.

\subsection{Morphological Characterization of As-Prepared Co-MOF on Ni Foam}

The morphology of the as-prepared sample produced by the solovothermal process was obtained by FE-SEM. It can be clearly observed in Figure 4a that the surface of Ni foam becomes rough compared with the bared Ni foam (Inset of Figure 4a), which is attributed to the formation of Co-MOF on Ni foam. More interestingly, as shown in Figure $4 \mathrm{~b}$, the high-density vertical-standing nanoarrays of Co-MOF with a 2D nanosheet morphology are fully covered on the surface of $\mathrm{Ni}$ foam. Furthermore, as we can see from the TEM image (Figure 4c), the 2D nanosheet morphology of as-prepared Co-MOF on $\mathrm{Ni}$ foam displays a unique parallelogram. Moreover, in Figure $4 \mathrm{~d}$, it can be found that 2D parallelogram-like Co-MOF is a layered structure. The EDX spectrum (Figure 4e) of as-prepared 2D Co-MOF exhibits the atom ratios of $\mathrm{C}, \mathrm{O}$, and Co elements, which are 64.98, 25.65 and $9.37 \%$, respectively. The corresponding elemental mapping images are shown in Figure $4 \mathrm{f}-\mathrm{i}$. It demonstrates that the $\mathrm{C}, \mathrm{O}$, and Co elements are uniformly distributed in our 2D parallelogram-like Co-MOF. 


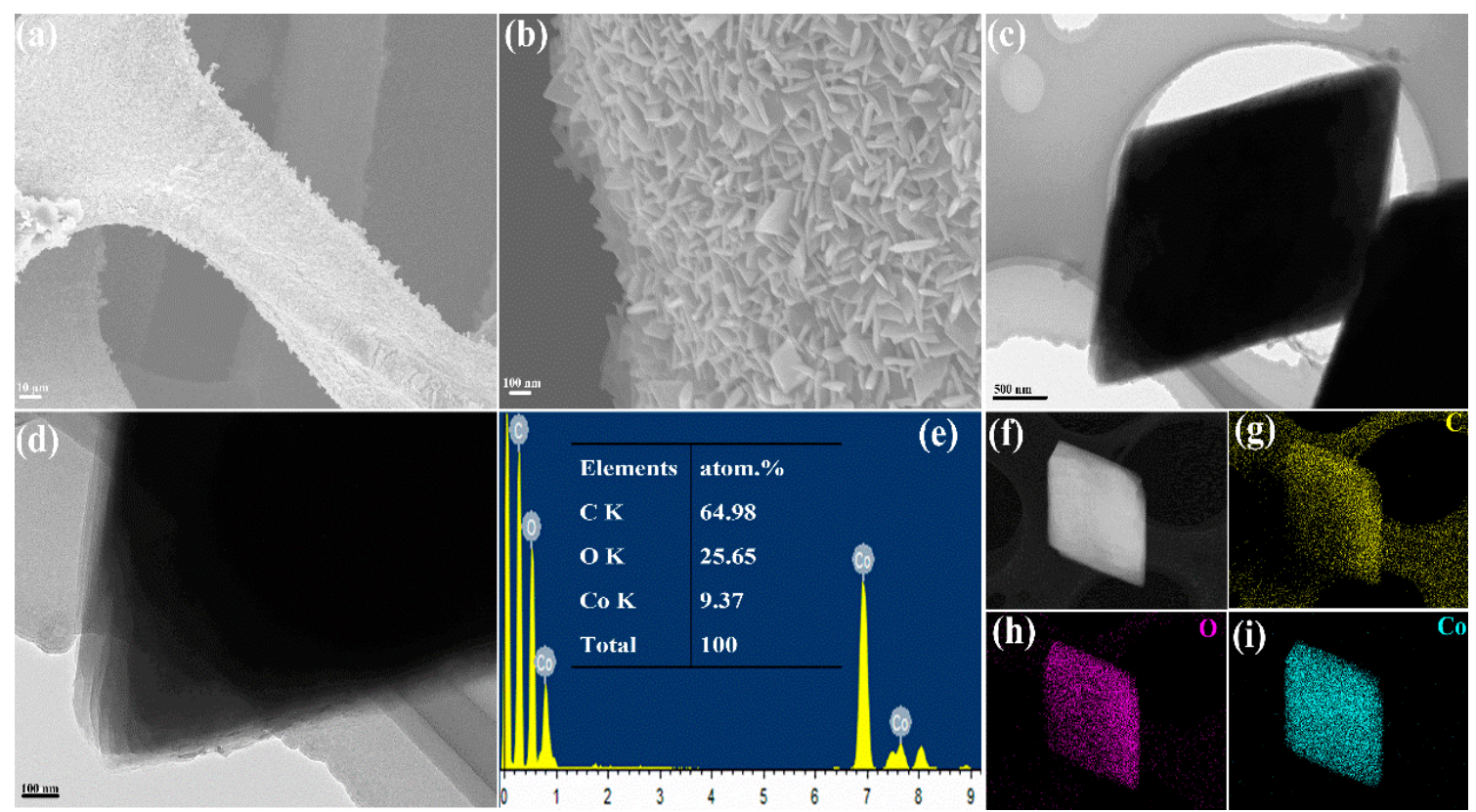

Figure 4. (a,b) FESEM images, (c,d) TEM images, (e) EDX spectrum, and (f-i) the corresponding elemental mapping images of $\mathrm{C}, \mathrm{O}$, and $\mathrm{Co}$ for 2D parallelogram-like Co-MOF on Ni foam.

\subsection{Electrochemical Capacitive Perforamcne of As-Prepared Co-MOF on Ni Foam}

Electrochemical capacitive performance of 2D parallelogram-like Co-MOF on Ni foam was studied by using a classical three-electrode system. As shown in Figure 5a, CV curves of as-prepared 2D MOF on Ni foam are obtained at different scan rates of 2, 5, 10, 20,30, and $50 \mathrm{mV} \mathrm{s}^{-1}$ with a potential range of $0-0.6 \mathrm{~V}$. It can be observed that the shapes of CV curves display a clear anodic and cathodic peak at $\sim 0.25$ and $\sim 0.45 \mathrm{~V}$, respectively, which may be attributed to the redox reaction of $\mathrm{Co}^{2+} / \mathrm{Co}^{3+}$ in $\mathrm{Co}-\mathrm{MOF}$ accompanied with the action of $\mathrm{OH}$ - during the electrochemical capacitive process $[45,46]$. Furthermore, the anodic and cathodic peaks can also be found at a high scan rate of $50 \mathrm{mV} \mathrm{s}^{-1}$, indicating the good reversibility of our 2D parallelogram-like $\mathrm{Co}-\mathrm{MOF}$ on $\mathrm{Ni}$ foam for the fast charge-charge process. Figure $5 \mathrm{~b}$ exhibits the discharge curves of $2 \mathrm{D}$ MOF on Ni foam at different current densities (from 2 to $50 \mathrm{~mA} \mathrm{~cm}{ }^{-2}$ ) under a potential range of $0-0.5 \mathrm{~V}$. It can be found that an obvious slope change $(0.32-0.45 \mathrm{~V})$ appears in the discharge curves, which agrees well with the $\mathrm{CV}$ results. The maximum areal capacitance values of 2D parallelogram-like Co-MOF on Ni foam can be reached at $582.0 \mathrm{mC} \mathrm{cm}^{-2}$ at a current density of $2 \mathrm{~mA} \mathrm{~cm}^{-2}$. Meanwhile, even at a very large current density of $50 \mathrm{~mA} \mathrm{~cm}^{-2}$, the capacitance value of as-prepared 2D Co-MOF electrode can still be $350.0 \mathrm{mC} \mathrm{cm}^{-2}$, indicating the good rate performance of $60.1 \%$ (as shown in Figure $5 \mathrm{c}$ ). A comparison between the reported results and our current study (based on active material mass: $1.23 \mathrm{mg} \mathrm{cm}^{-2}$ for our Co-MOF) is displayed in Table 1. It can be seen that our Co-MOF electrode materials exhibit better electrochemical capacitive performance. 
Table 1. A comparison of electrochemical capacitive performance for pristine MOF-based materials between the reported results and our current study (Based on active material mass: $1.23 \mathrm{mg} \mathrm{cm}^{-2}$ for our Co-MOF).

\begin{tabular}{|c|c|c|c|c|c|}
\hline Electrode & Synthetic Method & Morphology & Electrolyte & Capacitance/Capacity & Reference \\
\hline NiCo-MOF & Chemical method & Nanosheets & $2 \mathrm{M} \mathrm{KOH}$ & $1109 \mathrm{~F} \mathrm{~g}^{-1}$ at $0.5 \mathrm{~A} \mathrm{~g}^{-1}$ & [26] \\
\hline Mn-MOF & Hydrothermal & Crystalline & $6 \mathrm{M} \mathrm{KOH}$ & $433 \mathrm{~F} \mathrm{~g}^{-1}$ at $1 \mathrm{~A} \mathrm{~g}^{-1}$ & [28] \\
\hline Co-MOF@Graphene & $\begin{array}{l}\text { Ultrasonicate and } \\
\text { centrifugation }\end{array}$ & Nanoparticles & $6 \mathrm{M} \mathrm{KOH}$ & $549.96 \mathrm{~F} \mathrm{~g}^{-1}$ at $10 \mathrm{mV} \mathrm{s}^{-1}$ & [36] \\
\hline Co-MOF & Hydrothermal & Nanospheres & $1 \mathrm{M} \mathrm{NaOH}$ & $657 \mathrm{~F} \mathrm{~g}^{-1}$ at $0.5 \mathrm{~A} \mathrm{~g}^{-1}$ & [40] \\
\hline Co-MOF & Hydrothermal & Microspheres & $1 \mathrm{M} \mathrm{LiOH}$ & $553 \mathrm{~F} \mathrm{~g}^{-1}$ at $1 \mathrm{~A} \mathrm{~g}^{-1}$ & [42] \\
\hline Co-doped Ni-based MOF & Hydrothermal & Nanoflowers & $6 \mathrm{M} \mathrm{KOH}$ & $100 \mathrm{Fg}^{-1}$ at $1 \mathrm{~A} \mathrm{~g}^{-1}$ & [44] \\
\hline Mo\&polyoxometalate-MOF & Hydrothermal & $\begin{array}{l}\text { 2D layered } \\
\text { microstructure }\end{array}$ & $1 \mathrm{M} \mathrm{H}_{2} \mathrm{SO}_{4}$ & $249.0 \mathrm{~F} \mathrm{~g}^{-1}$ at $3 \mathrm{~A} \mathrm{~g}^{-1}$ & [47] \\
\hline MOF-5 & $\begin{array}{l}\text { Incipient wetness } \\
\text { technique }\end{array}$ & Nanoparticles & $1 \mathrm{M} \mathrm{H}_{2} \mathrm{SO}_{4}$ & $100 \mathrm{Fg}^{-1}$ at $5 \mathrm{mV} \mathrm{s}^{-1}$ & [48] \\
\hline Co-MOF & Hydrothermal & nanoarrays & $2 \mathrm{M} \mathrm{KOH}$ & $\begin{array}{c}946 \mathrm{~F} \mathrm{~g}^{-1} \text { at } 1.63 \mathrm{~A} \mathrm{~g}^{-1} \\
582.0 \mathrm{mC} \mathrm{cm}^{-2} \text { at } 2 \mathrm{~mA} \mathrm{~cm}^{-2}\end{array}$ & This Work \\
\hline
\end{tabular}

The electrochemical behavior of 2D parallelogram-like Co-MOF on $\mathrm{Ni}$ foam is further studied by fitting the $\mathrm{CV}$ curves. The following equation is used to fit the scan rate $(v$, $\left.\mathrm{mV} \mathrm{s}^{-1}\right)$ and peak current $\left(I_{p}, \mathrm{~mA} \mathrm{~cm}^{-2}\right)$ from CV curves [49-51].

$$
\begin{gathered}
I_{p}=a v^{b} \\
\log \left(I_{p}\right)=b \log (v)+\log (a)
\end{gathered}
$$

The slope $b$ for the relationship between $\log (I p)$ and $\log (v)$ is a constant, which can disclose the electrochemical charge storage mechanism for as-studied active electrode materials. When $b$ value equals to 0.5 , it means that the electrode current response is controlled by a diffusion process. When $b$ value equals to 1 , it is reprehensive of a capacitivecontrolled response. When $b$ value is between 0.5 and 1 , the capacitance contribution is attributed to the surface capacitive and diffusion processes. Figure $5 \mathrm{~d}$ exhibits the fitting $b$ values of 0.71 and 0.74 for the anode and cathode, respectively, suggesting that as-prepared 2D Co-MOF electrode displays the electrode reaction controlled by surface and diffusion processes. In order to further differentiate the contribution rate of the diffusion process and surface capacitive-controlled reaction, the following equation can be used [52,53].

$$
i(V)=k_{1} v+k_{2} v^{1 / 2}
$$

Figure 5e displays the $\mathrm{CV}$ curve at $20 \mathrm{mV} \mathrm{s}^{-1}$, and the capacitive contribution ratios are $57.0 \%, 68.7 \%, 74.6 \%, 81.7 \%$, and $88.0 \%$ (Figure $5 f$ ) at 2, 5, 10, 20, and $30 \mathrm{mV} \mathrm{s}^{-1}$, respectively. It can be observed that the surface capacitive response rises with the increased scan rate of $\mathrm{CV}$, indicating the diffusion process was delayed at a high scan rate. Therefore, we can conclude that the electrochemical charge storage process for our 2D parallelogram-like Co-MOF on a Ni foam electrode is controlled by a mixture of capacitor and battery-type properties. Cyclic stability of as-prepared 2D parallelogram-like Co-MOF on Ni foam is also tested at a high current density of $20 \mathrm{~mA} \mathrm{~cm}{ }^{-2}$. It can be observed that the initial capacitance value is $425.5 \mathrm{mC} \mathrm{cm}{ }^{-2}$ along with the increased capacity after 1000 cycles, which can be attributed to the adequate activation process. Then, the capacitance retention can be $82.6 \%$ compared with the initial capacitance value after 5000 cycles, indicating its good cyclic stability.

Based on the above-mentioned results, the good electrochemical capacitive performance for our 2D parallelogram-like Co-MOF on Ni foam may be attributed to the following reasons: (1) directly grown $\mathrm{Co}-\mathrm{MOF}$ on the surface of conductive $\mathrm{Ni}$ foam can guarantee the good electrical conductivity, which can help the electron transportation; (2) this self-supported nanostructure design can maximize active material utilization ( $\mathrm{Co}$ $\mathrm{MOF}$ ) without the polymer binder and conductive agents; (3) vertical standing Co-MOF nanoarrays with a $2 \mathrm{D}$ parallelogram-like morphology can provide abundant active surface 
areas to react with electrolyte ions; and (4) super-hydrophilic property of Co-MOF on $\mathrm{Ni}$ foam (as shown in Figure 5h,i) is advantageous to contact with the aqueous electrolyte.

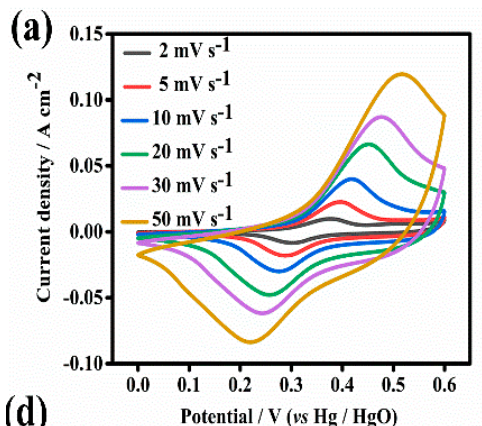

(d)
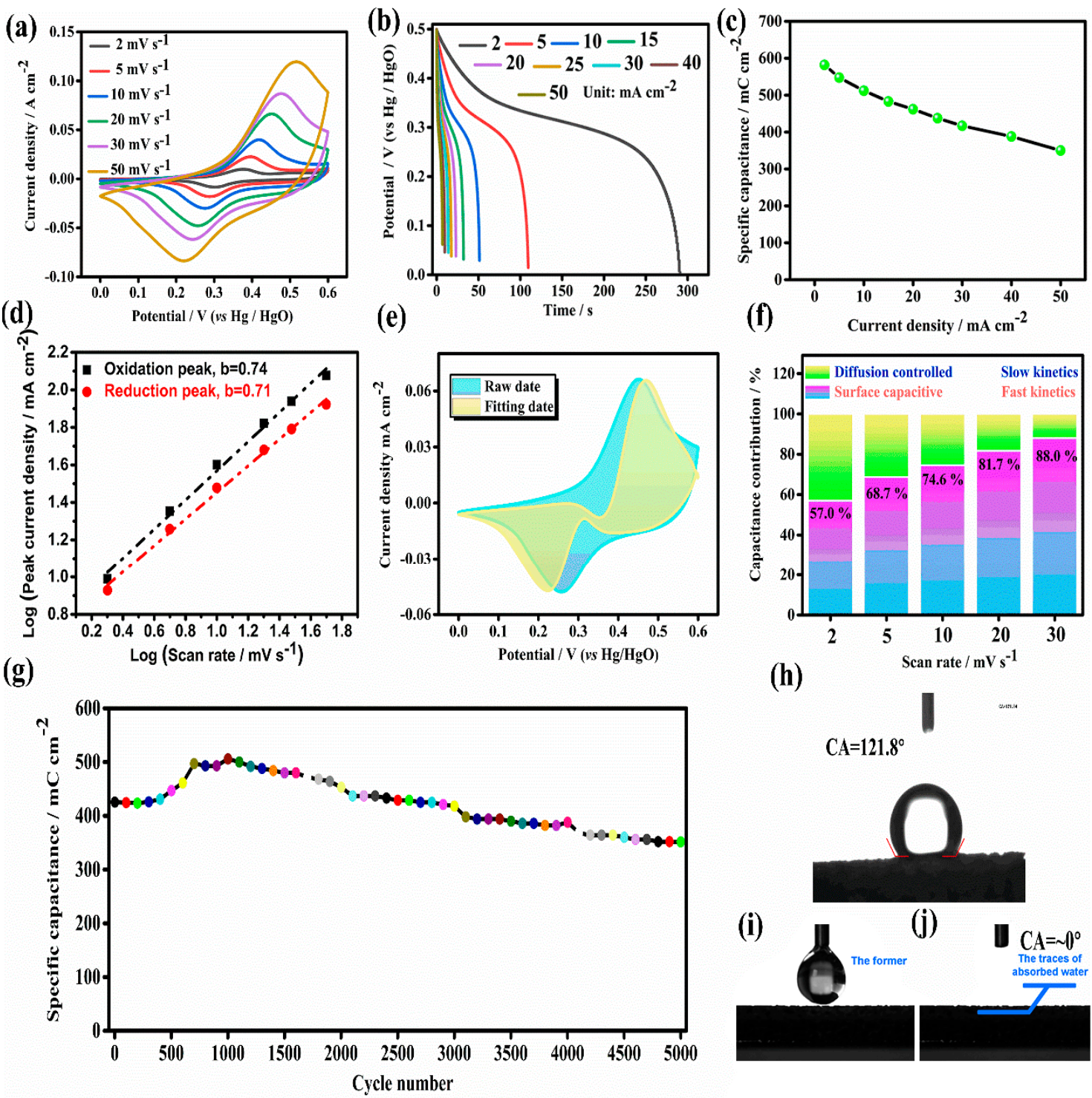

(h)

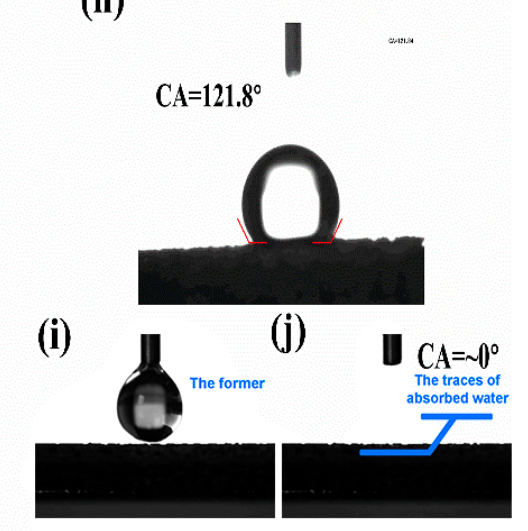

Figure 5. Electrochemical capacitive performance of 2D parallelogram-like Co-MOF on Ni foam using a classical threeelectrode system: (a) CV curves at different scan rates, (b) GCD curves at different current densities, (c) Specific area capacitance at a current density range from 2 to $50 \mathrm{~mA} \mathrm{~cm}^{-2}$, (d) Plots between Log (scan rate) and Log (peak current density), (e) Capacitive and diffusion currents at $20 \mathrm{mV} \mathrm{s}^{-1}$, (f) Contribution ratio of pseudocapacitive and diffusioncontrolled capacitance, (g) Cyclic stability at a current density of $20 \mathrm{~mA} \mathrm{~cm}^{-2}$ and the contact angle test of (h) bared Ni foam and $(\mathbf{i}, \mathbf{j})$ as-prepared Co-MOF on Ni foam.

\subsection{Electrochemical Perforamcne of AEC Device}

As shown in Figure 6a, an AEC device was assembled with our 2D parallelogram-like $\mathrm{Co}-\mathrm{MOF}$ on $\mathrm{Ni}$ foam as a cathode material and active carbon coated on $\mathrm{Ni}$ foam as an anode material, and electrochemical performance was tested in a $2 \mathrm{M} \mathrm{KOH}$ electrolyte. The CV curves of as-prepared Co-MOF cathode and active carbon anode are obtained at a scan rate of $10 \mathrm{mV} \mathrm{s}^{-1}$, as shown in Figure $6 \mathrm{~b}$. It can be found that the potential range of as-prepared Co-MOF cathode is from 0 to $0.6 \mathrm{~V}$, while the active carbon anode is -1 to $0 \mathrm{~V}$. Therefore, it can be expected that the suitable working voltage of our assembled AEC device can reach up to $1.6 \mathrm{~V}$, which can be further confirmed by $\mathrm{CV}$ curves at a scan rate of $50 \mathrm{mV} \mathrm{s}^{-1}$ with 
different voltage ranges obtained from Figure $6 c$. Subsequently, CV curves at different scan rate rage from 5 to $100 \mathrm{mV} \mathrm{s}^{-1}$ at a voltage range from $0-1.6 \mathrm{~V}$ are shown in Figure $6 \mathrm{~d}$. It can be observed that the shape of all CV curves almost keep unchanged with the increased scan rates, even at a high scan rate of $100 \mathrm{mV} \mathrm{s}^{-1}$, indicating the excellent performance rate of our assembled AEC device. Figure 6e exhibits the discharge curve for the device at a current density range from 1 to $15 \mathrm{~mA} \mathrm{~cm}^{-2}$. The areal specific capacitance values (Figure 6f) determined by the charge curves are 230.6, 226.3, 211.5, 207.0, 200.0, 195.0, 190.5, and $183.8 \mathrm{mF} \mathrm{cm}^{-2}$ at $1-15 \mathrm{~mA} \mathrm{~cm}^{-2}$, respectively. The high capacitance retention of $79.7 \%$ further supports the excellent capacitive characteristic for our Co-MOF-based AEC device. EIS measurement and the fitting results based on the equivalent circuit (Figure 6g, inset) for the AEC device are shown in Figure 6g. It can be seen that the plot display a small semicircle at the high-frequency region and a nearly vertical line at the low-frequency region. The fitting data show that the equivalent series resistance (ESR) value is 0.89 along with a small charge transfer resistance (Rct) of 0.02. These analyzes demonstrate that our AEC device displays good super-capacitive behavior. Especially in Ragone plots (Figure 6h) of energy and power density for our AEC device, the maximum energy density can reach up to $0.082 \mathrm{~mW} \mathrm{~cm}{ }^{-2}$ with a power density of $0.8 \mathrm{~mW} \mathrm{~cm}^{-2}$. Moreover, the energy density can still maintain $0.065 \mathrm{~mW} \mathrm{~cm}^{-2}$ at a high power density of $11.94 \mathrm{~mW} \mathrm{~cm}^{-2}$.
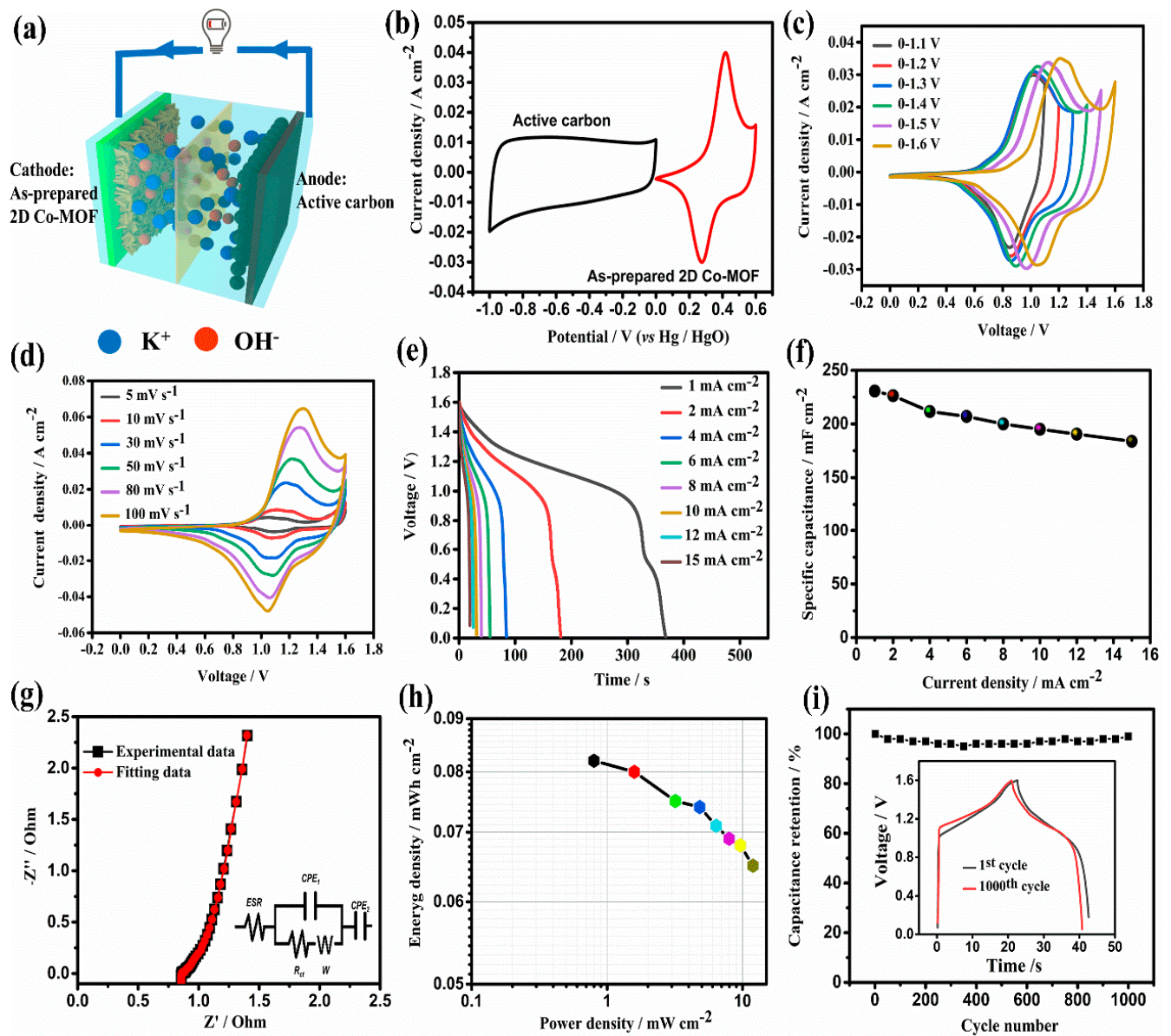

Figure 6. Electrochemical performance of 2D parallelogram-like Co-MOF on Ni foam/ / AC AEC device: (a) Illustration of asymmetric supercapacitor device using as-prepared 2D parallelogram-like Co-MOF on Ni foam and AC as a cathode and anode material, respectively, (b) 2D parallelogram-like Co-MOF and AC at the different potential windows at $10 \mathrm{mV} \mathrm{s}^{-1}$, (c) CV curves at a scan rate of $50 \mathrm{mV} \mathrm{s}^{-1}$ with different voltage ranges, (d) CV curves at different scan rates at a voltage range from 0-1.6 V, (e) Discharge curves at different current densities, (f) Specific capacitance varied from current densities, (g) EIS plots for experimental and fitting data, (h) Ragone plots of energy and power density, and (i) Cyclic performance at a current density of $15 \mathrm{~mA} \mathrm{~cm}^{-2}$, inset shows GCD curves for the first and 1000th cycle. 
The cyclic performance of our AEC device is also tested at a current density of $15 \mathrm{~mA} \mathrm{~cm}^{-2}$ for 1000 cycles. It shows a capacitance retention of nearly $100 \%$ after $1000 \mathrm{cy}-$ cles. The GCD curves for the initial and the 1000th cycle are almost overlapped, which further confirms the excellent cycling stability of our Co-MOF-based electrode materials. These results are comparable or higher to many reported pristine MOF-based electrocapacitive materials [54,55].

\section{Materials and Methods}

\subsection{Materials}

p-phthalic acid (PTA) was purchased from Energy Chemical Co, Ltd. (Shanghai, China). Nickel chloride hexahydrate $\left(\mathrm{CoCl}_{2} \cdot 6 \mathrm{H}_{2} \mathrm{O}\right)$, hydrochloric acid $(\mathrm{HCl}), \mathrm{N}, \mathrm{N}$-dimethyl formamide (DMF), and methanol were purchased from Tianjin Fuchen Chemical Reagent Co., Ltd. Nickel foam (surface density: $350 \mathrm{~g} \mathrm{~m}^{-2}$; thickness: $1.6 \mathrm{~mm}$ ) was brought from Shenzheng Kejing Star Technology Company (Shengzheng, China).

\subsection{Preparation of Co-MOF on Ni Foam}

In a typical experiment, $2.0 \mathrm{mmol}$ of $\mathrm{CoCl}_{2} \cdot 6 \mathrm{H}_{2} \mathrm{O}$ and $2.0 \mathrm{mmol}$ of PTA were dissolved in $40 \mathrm{~mL}$ of DMF. After stirring for $30 \mathrm{~min}$ at room temperature, $2.0 \mathrm{~mL}$ of high-purity water was slowly dropped into above-mentioned solution and stirred for $10 \mathrm{~min}$. Next, the solution was transferred into a Teflon-lined stainless steel autoclave. At the same time, the pretreated $\mathrm{Ni}$ foam $\left(1 \times 3 \mathrm{~cm}^{2}\right)$ was immediately immersed into an autoclave. After that, the autoclave was placed into an oven and maintained at a temperature of $120^{\circ} \mathrm{C}$ for $180 \mathrm{~min}$. After that, as-prepared Co-MOF on Ni foam was obtained by washing with DMF and methanol for at least three times. Finally, as-prepared samples were dried at $80^{\circ} \mathrm{C}$ for $12 \mathrm{~h}$ in the vacuum drying oven.

\subsection{Physical Characterization}

The crystalline structure of as-prepared samples was characterized by $\mathrm{X}$-ray diffraction (XRD) pattern carried out using a Bruker D8-Advanced X-ray instrument (Karlsruhe, Germany) with $\mathrm{Cu}-\mathrm{K} \alpha$ radiation $(\lambda=1.540598 \AA$ ). Fourier transform infrared (FTIR) spectroscopy was collected on a FTIR-650 spectrophotometer (Tianjin Gangdong Co., Ltd., Tianjin, China). The microstructure and morphology were observed by a field-emission scanning electron microscope (FESEM, Hitachi S4800, Tokyo, Japan) and transmission electron microscopy (TEM, FEI Tecnai G2 F30, Hillsboro, OR, USA). X-ray photoelectron spectrometer (XPS) was performed using Thermo Fisher ESCALAB 250 Xi (Waltham, MA, USA).

\subsection{Electrochemical Measurements}

Electrochemical measurements were carried out on a CHI660e electrochemical workstation (Shanghai CH Instruments Ins., Shanghai, China) in a classical three-electrode, along with as-prepared $\mathrm{Co}-\mathrm{MOF}$ on $\mathrm{Ni}$ foam as the work electrode, a Pt plate as the counter electrode, and an $\mathrm{Hg} / \mathrm{HgO}$ as the reference electrode. Next, $2 \mathrm{M} \mathrm{KOH}$ was chosen to be the electrolyte. Cyclic voltammetry (CV) measurements were displayed at different scan rate (2-50 $\left.\mathrm{mV} \mathrm{s}^{-1}\right)$ with a potential range from 0 to $0.6 \mathrm{~V}$. Galvanostatic charge discharge (GCD) curves were performed at different current densities $\left(2-50 \mathrm{~mA} \mathrm{~cm}{ }^{-2}\right)$ with a potential range from 0 to $0.5 \mathrm{~V}$.

The area specific capacitance $(C s)$ of as-prepared active $\mathrm{Co}-\mathrm{MOF}$ on a $\mathrm{Ni}$ foam electrode was calculated by the following equation:

$$
C_{s}=\frac{I \times \Delta t}{s}
$$

where $I, \Delta t$, and $s$ represent the discharge current (A), discharge time $(\mathrm{s})$, and the area $\left(\mathrm{cm}^{2}\right)$ of the electrode, respectively. 
The home-made ACS device was assembled by using as-prepared Co-MOF on Ni foam as the cathode and active carbon-coated Ni foam as the anode, with a cellulosic separator in between. The mass ratio of cathode to anode was determined according to the charge balance equation. The area energy density $E\left(\mathrm{Wh} \mathrm{cm}^{-2}\right)$ and power density $P$ $\left(\mathrm{W} \mathrm{cm}^{-2}\right.$ ) were calculated by the following equations:

$$
\begin{gathered}
E=\frac{C \Delta V^{2}}{2} \times \frac{1000}{3600} \\
P=\frac{E}{\Delta t} \times 3600
\end{gathered}
$$

\section{Conclusions}

In summary, vertical-standing Co-MOF nanoarrays with 2D parallelogram-like morphology on Ni foam were successfully fabricated via a simple one-step solovothermal method. The as-prepared Co-MOF on a Ni foam electrode displayed good electrochemical capacitive performance due to the self-supported nanostructure design, the intimate contact between active Co-MOF and conductive Ni foam, and super-hydrophilic property of Co-MOF on Ni foam. The practicality of our Co-MOF on Ni foam electrodes were confirmed by the assembled AEC device, which can achieve a maximum energy density of $0.082 \mathrm{~mW} \mathrm{~cm}^{-2}$ at a power density of $0.8 \mathrm{~mW} \mathrm{~cm}^{-2}$ with a capacitance retention of nearly $100 \%$ after 1000 cycles. This work will open up a simple method for preparing high-performance MOF-based energy storage materials.

Author Contributions: Conceptualization, L.L. and H.M.; methodology, Y.J. and L.L.; investigation, D.R.; writing—original draft preparation, L.L. and J.L.; writing-review and editing, Y.J. and K.Z.; visualization, J.L.; supervision, Y.J. and H.W.; funding acquisition, Q.Z. All authors have read and agreed to the published version of the manuscript.

Funding: This research was funded by the National Natural Science Foundation of China (No. 62075002).

Institutional Review Board Statement: Not applicable.

Informed Consent Statement: Not applicable.

Data Availability Statement: Data available on request.

Conflicts of Interest: The authors declare no conflict of interest.

Sample Availability: Samples of the compounds are unavailable from the authors.

\section{References}

1. Wu, N.; Bai, X.; Pan, D.; Dong, B.; Wei, R.; Naik, N.; Patil, R.; Guo, Z. Recent advances of asymmetric supercapacitors. Adv. Mater. Interfaces 2021, 8, 2001710. [CrossRef]

2. Huang, Y.; Zeng, Y.; Yu, M.; Liu, P. Recent smart methods for achieving high-energy asymmetric supercapacitors. Small 2018, 2, 1700230. [CrossRef]

3. Sun, J.; Wu, C.; Sun, X.; Hu, H.; Zhi, C.; Hou, L.; Yuan, C. Recent progresses in high-energy-density all pseudocapacitive-electrodematerials-based asymmetric supercapacitors. J. Mater. Chem. A 2017, 5, 9443-9464. [CrossRef]

4. Wang, Y.; Song, Y.; Xia, Y. Electrochemical capacitors: Mechanism, materials, systems, characterization and applications. Chem. Soc. Rev. 2016, 45, 5925-5950. [CrossRef]

5. Simon, P.; Gogotsi, Y. Perspectives for electrochemical capacitors and related devices. Nat. Mater. 2020, 19, 1151-1163. [CrossRef] [PubMed]

6. Hall, P.; Mirzaeian, M.; Fletcher, S.; Sillars, F.; Rennie, A.; Shitta-Bey, G.; Wilson, G.; Cruden, A.; Carter, R. Energy storage in electrochemical capacitors: Designing functional materials to improve performance. Energy Environ. Sci. 2010, 3, 1238-1251. [CrossRef]

7. Yu, G.; Xie, X.; Pan, L.; Bao, Z.; Cui, Y. Hybrid nanostructured materials for high-performance electrochemical capacitors. Nano. Energy 2013, 2, 213-234. [CrossRef]

8. Evanko, B.; Boettcher, S.; Yoo, S.; Stucky, G. Redox-enhanced electrochemical capacitors: Status, opportunity, and best practices for performance evaluation. ACS Energy Lett. 2017, 2, 2518-2590. [CrossRef]

9. Wang, J.; Dong, S.; Ding, B.; Wang, Y.; Hao, X.; Dou, H.; Xia, Y.; Zhang, X. Pseudocapacitive materials for electrochemical capacitors: From rational synthesis to capacitance optimization. Nat. Sci. Rev. 2017, 4, 71-90. [CrossRef] 
10. Wu, Z.; Ren, W.; Wang, D.; Li, F.; Liu, B.; Cheng, H. High-energy $\mathrm{MnO}_{2}$ nanowire/graphene and graphene asymmetric electrochemical capacitors. ACS Nano 2010, 4, 5835-5842. [CrossRef]

11. Shen, S.; Jiang, H.; Cheng, Q.; Wang, G.; Petr, S.; Li, C. Amorphous vanadium oxides with metallic character for asymmetric supercapacitors. Chem. Eng. J. 2021, 403, 126380.

12. Zhang, H.; Lin, L.; Wu, B.; Hu, N. Vertical carbon skeleton introduced three-dimensional $\mathrm{MnO}_{2}$ nanostructured composite electrodes for high-performance asymmetric supercapacitors. J. Power Sources 2020, 476, 228527. [CrossRef]

13. Shao, Y.; El-Kady, M.; Sun, J.; Li, Y.; Zhang, Q.; Zhu, M.; Wang, H.; Dunn, B.; Kaner, R. Design and mechanisms of asymmetric supercapacitors. Chem. Rev. 2018, 118, 9233-9280. [CrossRef]

14. Zhang, G.; Xiao, X.; Li, B.; Xue, H.; Pang, H. Transition metal oxides with one-dimensional/one-dimensional-analogue nanostructures for advanced supercapacitors. J. Mater. Chem. A 2017, 5, 8155-8186. [CrossRef]

15. Wang, T.; Chen, H.; Yu, F.; Zhao, X.; Wang, H. Boosting the cycling stability of transition metal compounds-based supercapacitors. Energy Storage Mater. 2019, 16, 545-573. [CrossRef]

16. He, W.; Wang, C.; Li, H.; Deng, X.; Xu, X.; Zhai, T. Ultrathin and porous $\mathrm{Ni}_{3} \mathrm{~S}_{2} / \mathrm{CoNi}_{2} \mathrm{~S}_{4} 3 \mathrm{D}$-network structure for superhigh energy density asymmetric supercapacitors. Adv. Energy Mater. 2017, 7, 1700983. [CrossRef]

17. Li, S.; Yu, C.; Yang, J.; Zhao, C.; Zhang, M.; Huang, H.; Liu, Z.; Guo, W.; Qiu, J. A superhydrophilic "nanoglue" for stabilizing metal hydroxides onto carbon materials for high-energy and ultralong-life asymmetric supercapacitors. Energy. Environ. Sci. 2017, 10, 1958-1965. [CrossRef]

18. Li, X.; Elshahawy, A.; Guan, C.; Wang, J. Metal phosphides and phosphates-based electrodes for electrochemical supercapacitors. Small 2017, 13, 1701530. [CrossRef] [PubMed]

19. Liang, H.; Xia, C.; Jiang, Q.; Gandi, A.; Schwingenschlögl, U.; Alshareef, H. Low temperature synthesis of ternary metal phosphides using plasma for asymmetric supercapacitors. Nano Energy 2017, 35, 331-340. [CrossRef]

20. Zhang, X.; Wu, A.; Wang, X.; Tian, C.; An, R.; Fu, H. Porous NiCoP nanosheets as efficient and stable positive electrodes for advanced asymmetric supercapacitors. J. Mater. Chem. A 2018, 6, 17905-17914. [CrossRef]

21. Gu, Y.; Fan, L.; Huang, J.; Geng, C.; Lin, J.; Huang, M.; Huang, Y.; Wu, J. N-doped reduced graphene oxide decorated NiSe 2 nanoparticles for high-performance asymmetric supercapacitors. J. Power. Sources 2019, 425, 60-68. [CrossRef]

22. Chen, Z.; Yang, Y.; Ma, Z.; Zhu, T.; Liu, L.; Zheng, J.; Gong, X. All-solid-state asymmetric supercapacitors with metal selenides electrodes and ionic conductive composites electrolytes. Adv. Funct. Mater. 2019, 29, 1904182. [CrossRef]

23. Li, K.; Wang, X.; Li, S.; Urbankowski, P.; Li, J.; Xu, Y. Gogotsi. An ultrafast conducting polymer@MXene positive electrode with high volumetric capacitance for advanced asymmetric supercapacitors. Small 2020, 16, 1906851. [CrossRef]

24. Snook, G.; Kao, P.; Best, A. Conducting-polymer-based supercapacitor devices and electrodes. J. Power Sources 2011, 196, 1-12. [CrossRef]

25. Li, K.; Wang, X.; Wang, X.; Liang, M.; Nicolosi, V.; Xu, Y.; Gogotsi, Y. All-pseudocapacitive asymmetric MXene-carbon-conducting polymer supercapacitors. Nano Energy 2020, 75, 104971. [CrossRef]

26. Liu, Y.; Wang, Y.; Chen, Y.; Wang, C.; Guo, L. NiCo-MOF nanosheets wrapping polypyrrole nanotubes for high-performance supercapacitors. Appl. Surf. Sci. 2020, 507, 145089. [CrossRef]

27. Dai, F.; Wang, X.; Zheng, S.; Sun, J.; Huang, Z.; Xu, B.; Fan, L.; Wang, R.; Sun, D.; Wu, Z. Toward high-performance and flexible all-solid-state micro-supercapacitors: MOF bulk vs. MOF nanosheets. Chem. Eng. J. 2021, 413, 127520. [CrossRef]

28. Feng, C.; Lv, C.; Zhao, H.; Li, Z.; Xie, W.; Sun, L.; Wang, Y. Structural elucidation and supercapacitive performance on a Mn (II)-based MOF. Cryst. Growth Des. 2020, 20, 5682-5687. [CrossRef]

29. Zhang, X.; Yang, S.; Lu, W.; Lei, D.; Tian, Y.; Guo, M.; Mi, P.; Qu, N.; Zhao, Y. MXenes induced formation of Ni-MOF microbelts for high-performance supercapacitors. J. Colloid. Interf. Sci. 2021, 592, 95-102. [CrossRef] [PubMed]

30. Yang, Q.; Wang, Q.; Long, Y.; Wang, F.; Wu, L.; Pan, J.; Han, J.; Lei, Y.; Shi, W.; Song, S. In situ formation of Co9S8 quantum dots in MOF-derived ternary metal layered double hydroxide nanoarrays for high-performance hybrid supercapacitors. Adv. Energy Mater. 2020, 10, 1903193. [CrossRef]

31. Gu, J.; Sun, L.; Zhang, Y.; Zhang, Q.; Li, X.; Si, H.; Shi, Y.; Sun, C.; Gong, Y.; Zhang, Y. MOF-derived Ni-doped CoP@C grown on CNTs for high-performance supercapacitors. Chem. Eng. J. 2020, 385, 123454. [CrossRef]

32. Wang, D.; Tian, L.; Huang, J.; Li, D.; Liu, J.; Xu, Y.; Ke, H.; Wei, Q. “One for two" strategy to prepare MOF-derived NiCo ${ }_{2} \mathrm{~S}_{4}$ nanorods grown on carbon cloth for high-performance asymmetric supercapacitors and efficient oxygen evolution reaction. Electrochim. Acta 2020, 334, 135636. [CrossRef]

33. Sheberla, D.; Bachman, J.; Elias, J.; Sun, C.; Shao-Horn, Y.; Dincă, M. Conductive MOF electrodes for stable supercapacitors with high areal capacitance. Nat. Mater. 2017, 16, 220-224. [CrossRef] [PubMed]

34. Azadfalah, M.; Sedghi, A.; Hosseini, H.; Kashani, H. Cobalt based metal organic framework/graphene nanocomposite as high performance battery-type electrode materials for asymmetric supercapacitors. J. Energy Storage 2021, 33, 101925. [CrossRef]

35. Xu, S.; Liu, R.; Shi, X.; Ma, Y.; Hong, M.; Chen, X.; Wang, T.; Li, F.; Hu, N.; Yang, Z. A dual CoNi MOF nanosheet/nanotube assembled on carbon cloth for high performance hybrid supercapacitors. Electrochim. Acta 2020, 342, 136124. [CrossRef]

36. Zhu, G.; Wen, H.; Ma, M.; Wang, W.; Yang, L.; Wang, L.; Shi, X.; Cheng, X.; Sun, X.; Yao, Y. A self-supported hierarchical $\mathrm{Co}-\mathrm{MOF}$ as a supercapacitor electrode with ultrahigh areal capacitance and excellent rate performance. Chem. Commun. 2018, 54, 10499-10502. [CrossRef] [PubMed] 
37. Wang, Z.; Gao, C.; Liu, Y.; Li, D.; Chen, W.; Ma, Y.; Wang, C.; Zhang, J. Electrochemical performance and transformation of Co-MOF/reduced graphene oxide composite. Mater. Lett. 2017, 193, 26-219. [CrossRef]

38. Zhang, X.; Qu, N.; Yang, S.; Lei, D.; Liu, A.; Zhou, Q. Cobalt induced growth of hollow MOF spheres for high performance supercapacitors. Mater. Chem. Front. 2021, 5, 482-491. [CrossRef]

39. Wang, Y.; Liu, Y.; Wang, H.; Liu, W.; Li, Y.; Zhang, J.; Hou, H.; Yang, J. Ultrathin NiCo-MOF nanosheets for high-performance supercapacitor electrodes. ACS Appl. Energy Mater. 2019, 2, 2063-2071. [CrossRef]

40. Zhang, H.; Wang, J.; Sun, Y.; Zhang, X.; Yang, H.; Lin, B. Wire spherical-shaped Co-MOF electrode materials for high-performance all-solid-state flexible asymmetric supercapacitor device. J. Alloy. Comp. 2021, 879, 160423. [CrossRef]

41. Yang, C.; Li, X.; Yu, L.; Liu, X.; Yang, J.; Wei, D. A new promising Ni-MOF superstructure for high-performance supercapacitors. Chem. Commun. 2020, 56, 1803-1806. [CrossRef]

42. Zhang, H.; Sun, Y.; Zhang, X.; Yang, H.; Lin, B. A new straightforward uncalcined approach for morphology modulating to enhance the electrical capacity performance of Co-MOF. Electrochim. Acta 2021, 389, 138684. [CrossRef]

43. Jia, R.; Zhao, C.; Huang, Z.; Liu, X.; Wang, D.; Hui, Z.; Xu, X. An in situ growth strategy of NiCo-MOF nanosheets with more activity sites for asymmetric supercapacitors. Ionics 2020, 26, 6309-6318. [CrossRef]

44. Wang, J.; Zhong, Q.; Xiong, Y.; Cheng, D.; Zeng, Y.; Bu, Y. Fabrication of 3D Co-doped Ni-based MOF hierarchical micro-flowers as a high-performance electrode material for supercapacitors. Appl. Surf. Sci. 2019, 483, 1158-1165. [CrossRef]

45. Yang, J.; Ma, Z.; Gao, W.; Wei, M. Layered structural Co-based MOF with conductive network frames as a new supercapacitor electrode. Chem. Eur. J. 2017, 23, 631-636. [CrossRef]

46. Chu, X.; Meng, F.; Deng, T.; Lu, Y.; Bondarchuk, O.; Sui, M.; Feng, M.; Li, H.; Zhang, W. Mechanistic insight into bimetallic CoNi-MOF arrays with enhanced performance for supercapacitors. Nanoscale 2020, 12, 5669-5677. [CrossRef] [PubMed]

47. Chai, D.; Xin, J.; Li, B.; Pang, H.; Ma, H.; Li, K.; Xiao, B.; Wang, X.; Tan, L. Mo-Based crystal POMOFs with a high electrochemical capacitor performance. Dalton Trans. 2019, 48, 13026-13033. [CrossRef]

48. Liu, B.; Shioyama, H.; Jiang, H.; Zhang, X.; Xu, Q. Metal-organic framework (MOF) as a template for syntheses of nanoporous carbons as electrode materials for supercapacitor. Carbon 2010, 48, 456-463. [CrossRef]

49. Augustyn, V.; Come, J.; Lowe, M.; Kim, J.; Taberna, P.; Tolbert, S.; Abruña, H.; Simon, P.; Dunn, B. High-rate electrochemical energy storage through Li+ intercalation pseudocapacitance. Nat. Mater. 2013, 12, 518-522. [CrossRef] [PubMed]

50. Brezesinski, T.; Wang, J.; Tolbert, S.; Dunn, B. Ordered mesoporous $\alpha$-MoO3 with iso-oriented nanocrystalline walls for thin-film pseudocapacitors. Nat. Mater. 2010, 9, 146-151. [CrossRef]

51. Wang, J.; Polleux, J.; Lim, J.; Dunn, B. Pseudocapacitive contributions to electrochemical energy storage in $\mathrm{TiO}_{2}(\mathrm{Anatase})$ nanoparticles. J. Phys. Chem. C. 2007, 111, 14925-14931. [CrossRef]

52. Mao, Z.; Wang, H.; Chao, D.; Wang, R.; He, B.; Gong, Y.; Fan, H. $\mathrm{Al}_{2} \mathrm{O}_{3}$-assisted confinement synthesis of oxide/carbon hollow composite nanofibers and application in metal-ion capacitors. Small 2020, 16, 2001950. [CrossRef]

53. Xu, D.; Chao, D.; Wang, H.; Gong, Y.; Wang, R.; He, B.; Hu, X.; Fan, H. Flexible quasi-solid-state sodium-ion capacitors developed using 2D metal-organic-framework array as reactor. Adv. Energy Mater. 2018, 8, 1702769. [CrossRef]

54. Banerjee, P.; Lobo, D.; Middag, R.; Ng, W.; Shaibani, M.; Majumder, M. Electrochemical capacitance of Ni-doped metal organic framework and reduced graphene oxide composites: More than the sum of its parts. ACS Appl. Mater. Interfaces 2015, 7, 3655-3664. [CrossRef]

55. Choi, K.; Jeong, H.; Park, J.; Zhang, Y.; Kang, J.; Yaghi, O. Supercapacitors of nanocrystalline metal-organic frameworks. ACS Nano 2014, 8, 7451-7457. [CrossRef] [PubMed] 